\title{
Designing User Learning Experience in Virtual Worlds: The Young Europeans for Democracy Serious Application
}

\author{
Gonçalo Cruz $^{1,2}$, Ana Maia ${ }^{1,3}$, Leonel Morgado ${ }^{1,2}$, Benjamim Fonseca ${ }^{1,2}$, \\ Hugo Paredes ${ }^{1,2}$, Fernando Bessa ${ }^{1,4}$, Clara Rodrigues ${ }^{5}$, and Paulo Martins ${ }^{1,2}$ \\ ${ }^{1}$ University of Trás-os-Montes e Alto Douro, \\ Apartado 1013, Quinta de Prados, \\ 5001-801 Vila Real, Portugal \\ \{goncaloc, margaridam, leonelm, benjaf, \\ hparedes, fbessa, pmartins\} @utad.pt \\ 2 INESC TEC - Associate Laboratory coordinated by INESC Porto \\ (Institute for Systems and Computer Engineering of Porto), Campus da FEUP, \\ Rua Dr. Roberto Frias, 378, \\ 4200-465 Porto, Portugal \\ ${ }^{3}$ CIDTFF - Research Centre Didatics and Technology in Education of Trainers, \\ University of Aveiro, \\ Campus Universitário, \\ 3810-193 Aveiro, Portugal \\ ${ }^{4}$ CETRAD - Centre for Transdisciplinary Development Studies, \\ Rua Dr. Manuel Cardona, \\ 5000-558 Vila Real, Portugal \\ ${ }^{5}$ Future Balloons Unipessoal LDA, \\ Avenida 5 de Janeiro 12/2C, Cova, \\ 3090-705 Figueira da Foz, Portugal \\ clara.rodrigues@gmail.com
}

\begin{abstract}
In this paper, we present the user experience design of Young Europeans for Democracy (YED) serious application. Facing the actually need to support young citizens understanding and participation in Europe, schools have a key role on European studies integration. Accordingly to the growing opportunities of applying technology for training and education, we propose a serious application in a open-source 3D Virtual World environment solution, adopting a problem-based learning approach, role-playing dynamics and group work tasks. The main goal was to design a meaningfully user experience, increasing the students motivation and engagement for learning different knowledge on the topics of European Studies. Some preliminary results are presented, based on participatory observation within the use of the serious application.
\end{abstract}

Keywords: European Studies, Virtual Worlds, Open Simulator, User learning experience, Human-Computer Interaction. 


\section{Introduction}

Schools are organizations entrusted with education of our children and youths, including their citizenship, particularly as European union citizens. Teachers are the connectors between Society - its organizational, historical, social, cultural, legal and economic dimensions - and students as users of those references. They have to promote awareness on how European politics, democracy, free market or free mobility, intercultural dialogue, the Euro, and other innovations changed the meaning to be an European citizen. This is a hard job because of its nature, very intangible, and also due the discomfort of teachers with European studies, or even the lack of motivation by students.

We contend that the pedagogical approaches to develop awareness and understanding of the values involved in European citizenship have to go beyond the lecture format and should take a different kind of approach: students need opportunities to perceive those values in different learning contexts and ways, through problem-based learning, role-playing dynamics and group work tasks. Assuming this, we present the ongoing project Young Europeans for Democracy (YED), which intends to provide schools and teachers with innovative resources and know-how related to new forms of teaching about European Union. Promoting youths as active agents of their own learning, and giving them the opportunity to experience their role as European citizens in an immersive 3D learning environment, we have developed a serious application in the Open Simulator 3D Virtual World.

The Section 2 presents related research work on European Studies integration, 3D Virtual Worlds for serious applications and User learning experience in 3D Virtual Worlds, all of which lie at the foundation of our study. Afterwards, in Section 3, we describe the main phases of the YED project, focusing on the user learning experience design within the development of the serious application. And finally, in Section 4, we identify some preliminary results and establish the research agenda for future improvements of the work.

\section{Background}

\subsection{European Studies Integration}

Accordingly to the European Commission, a past study revealed the pessimism of European Union citizens about the situation in their country and the future as causes indicating the rapidity of changes taking place, namely: the large uncertainties about the consequences, whether economic or technological developments; the fear regarding the use and effects of new technologies; the risks produced by pollution and genetic manipulation; the feeling of loss of values and social cohesion - especially the growth of poverty, loss of importance of forms of solidarity and friendliness, isolation of young, growing insecurity and fear of the effects of immigration; and the pernicious results of economic liberalism - whose effects are felt with special 
virulence in essential public services (health, education, public transport) and social cohesion in a society increasingly more subordinated to the power and interests of finance and big business [1].

Considering that, in a more recent study [2], young Europeans demonstrated clear pessimism about their expectations for the next 20 years, though less severe than among older citizens. It seems indisputable that Europe is steeped in what threatens to be the largest ever faced deadlock since the Schumann Declaration [3]. Given the skepticism of young Europeans about their future, a situation that endangers the credibility of European institutions and their rulers. It is necessary that schools and teachers develop initiatives and approaches aimed to provide ways of awareness and understanding of the historical, social, legal, cultural, economic and political dynamics, in which Europe is steeped.

If that is critical to the Society, schools have to promote European Integration studies as a cross-disciplinary field, covering the study of the origin and evolution of the European Union, as a whole, in all of its aspects. These include the analysis of both the internal and external dimension of European integration, including the European Union' role in the dialogue between peoples and cultures, in the youths mobility and integration into the labor market, in the citizens fundamental rights promotion, and others.

\subsection{D Virtual Worlds for Serious Applications}

Virtual Worlds (VWs), such as Second Life or Open Simulator, are computergenerated environments, in which multiple users navigate, interact and communicate having a form of embodied representation [4]. Although not been created with that purpose, they offer many advantages for the development of different kind of serious applications, such as training [5]. In this sense, with the growing opportunities of applying educational technology, the use of these environments for training and education was also increased [6][7][8][9].

There is a possibility of participants playing different roles [10] in a problem-based learning methodology [11], with group dynamics and task-based approach [12], promoted by an active and collaborative knowledge construction process, where students can control their own learning with a high level of engagement [13]. That can be adopted for experiential and social learning, particularly in areas such as selfdevelopment, thinking skills, and critical civic conscience [14][11].

In fact, it is possible to apply a wide range of learning strategies, considering the versatility of these environments [15]. Having an representation of themselves, through an avatar, students being able to move within space and context with multiple sensory inputs, such as visual, auditory and tactile [13]. They also can communicate and participate in real time events and tasks, building objects and simulated- reality scenarios, seeing immediately the results of their own interaction with the environment and peers in a 3D way [14][11].

From a comparative point of view, virtual worlds such as Second Life and Open Simulator can't be confronted: the first is a social world and the second is a server software. However, Open Simulator can be a good solution to adopt. This platform is both open source and freely available for installation at organizations, such as schools 
own servers, allowing them to start their own project, provided only to a specific educational community, and solving problems related to content protection, users age, backup policies, currency costs, among others [16].

\subsection{User Learning Experience in 3D Virtual Worlds}

As we saw above, a set of learning affordances from VWs are also pointed out by Dalgarno and Lee [17]. These environments can facilitate learning experience tasks that would be impractical to undertake in the real world, the transfer of knowledge and skills to real situations through contextualization of learning, and they also lead to increased intrinsic motivation, engagement, and effective collaborative learning than is possible with 2-D alternatives.

Although, some negative findings suggest that these environments promote great social presence rather than cognitive, showing that learning was not enhanced and the technology became a distraction [18][4]. For instance, in order to achieve higher levels of cognitive presence, the activities must be well structured and the student roles clearly defined [19].

There is still a lack of validated design principles and guidelines for developing learning spaces within VWs. User experience evaluation studies are scarce, and only a few studies have been reported in the literature related to interaction design and usability [20][21]. There are some studies related to social and motivational aspects of learning in VWs [22][18], that identifies learners pre-analysis and task-orientation as a path to increase student engagement in 3D VWs. Other researchers have focused on interaction with technological features of VWs, e.g., multisensory representation can help learners' interest, fun, ability to navigate [23][24], interaction with data gloves [25], etc.

An empirical research identifies interaction design and usability as key factors influencing the learning experience [26] . From the fields of urban planning, HumanComputer Interaction, Web usability, geography and psychology, the authors propose a cross-disciplinary set of design principles and guidelines for 3D learning spaces: 1Conform the affordance of learning spaces and objects; 2- Have a story or narrative for the space; 3- Use real world metaphors; 4- Consider ambience and aesthetics of the learning space; 5- Realism for familiarity and comfort; 6- Orient the user at the landing or entry point; 7- Avoid spaces that can trigger phobic reaction or don't provide and easy exit; 8- "Design the form following the function".

\section{The Young Europeans for Democracy Project}

The Young Europeans for Democracy (YED) project aims to support the educational community, at vocational and secondary schools, in the process of European studies integration to promote an active citizenship between Portuguese youths. From our team prior experience in the field, we propose the design of $3 \mathrm{D}$ virtual learning scenarios through a problem-based learning methodology, with role-playing and group dynamics approaches. The main goal was the development of a serious application to train young students and their teachers, in the achievement of a wide range of knowledge and skills related to the European Union studies. 
The YED project is a partnership between the University of Trás-os-Montes e Alto Douro (UTAD) and 5 vocational/secondary schools from Vila Real, Northeastern Portugal. During the project design and implementation, a set of different stakeholders will be involved. From the UTAD, a multidisciplinary team of 10 researchers (Professors, Tutors, Programmers and Designers) will design and implement the project with 11 teachers and 236 students, aged between 15 and 18 years old. Started on February 2012, the project execution is scheduled for one year, based on a five-step methodology.

\subsection{Need Analysis}

The first step was designed to collect and understand the students needs, regarding European citizenship and European studies integration. It aimed to identify the learning priority areas, in which the design and implementation of the serious application are supported - a similar process was developed with SME managers [27].

For that purpose, 4 workshops were made with 70 students of the 5 schools. These one hour sessions have included group tasks with brainstorming dynamics, open discussions and corresponding question exercises, in order to measure the students' prior knowledge, skills and perceptions on the topics of European Union historical, political, economic, social, legal, geographical and cultural dimensions. The approach was to present a wide range of problematic scenarios, regarding the European students' context and daily life, to be solved or discussed by them.

Based on a participatory observation methodology, we have identified a strongest lack of motivation by students to engage in the proposed learning tasks. We also understand, in a general way, that students show poor perceptions and didn't have the satisfactory thinking skills in order to discuss and solve the problems (less observed when they dealing with the historical, social, geographical and cultural dimensions of European Union). Therefore, we have defined a set of main learning priority areas and goals, constituted by a multidisciplinary field, that addresses a wide range of skills and knowledge, namely: 1- European Union history and organization (Know and understand the major treaties and EU symbols, the role of EU political, juridical, and economic institutions in its social context, etc.); 2- European fundamental rights (Interpret, understand and apply the fundamental rights as European youths to their own daily life's); 3- Intercultural dialogue (Know the EU role in the promotion of the main EU Member-states cultural references, like language, monuments and historical facts, personalities, gastronomy, religion, economic and political system, etc.); 4Students and workers mobility (Analysis the opportunities that EU programs offer to European youth students and workers in other Member-states); and 5- Single currency and internal market (Confront the advantages and disadvantages of Euro currency and interpret the origin causes of European internal market crisis).

We also use the virtual world Second Life (SL viewer version 2.0) in the sessions, only to familiarize and provide the first contact with a similar environment to Open Simulator, and identify students' needs towards the use of technology. In general, the students' engagement was clearly higher than the expected and they easily have 
executed a set of simple tasks, like communication with peers (eg. chat and IM) and in-world orientation (eg. movement controls, teleport, interaction with objects and camera control tasks).

\subsection{Teachers Professional Training}

We developed a set of training sessions to the eleven teachers involved in the project, into a different courses: 1 - We delivered a 25 hours b-learning course, with particular focus on teaching skills for the main priority learning areas and goals, previously identified in the first step. From open and participatory discussions about the topic contents, to the exercise of learning design skills, particularly with the use of education technology; 2- We have also delivered a 3 hours short-course, focused on the use of $3 \mathrm{D}$ virtual worlds as educational environments. The main goal was to present and exercise different possibilities of in-world learning scenarios, from simple activities (like in the first step with the youths), to a more complex tasks, like objects building and avatar customization (eg. forms, textures, positions, etc.).

\subsection{Design and Development of the Serious Application}

Based on some user experience design principles and guidelines presented in the literature [21][25][26], and accordingly to the main priority learning areas and goals, previously identified in the first step with students, we designed the serious application. Adopting a problem-based learning approach, role-playing tasks and group work dynamics, we propose a set of 5 different designed in-world and well structured learning activities (different spaces, learning goals, ways and kinds of interaction, score and feedback systems, time, and workload expectation) within a narrative through different simulated real-world scenarios (students have to achieve an historical perspective of their identity as youth European Union citizens; identify the necessary documents to travel to other European Union Member-states, geographically located, in order to explore different cultural aspects; help community in the promotion of the fundamental rights that they have as European Union citizens, regarding their own daily life's context and routines, etc.).

The serious application covers 8 virtual islands in UTAD's Open Simulator server, which one called by the name of different European Union Member-states, namely: Portugal, United Kingdom, Belgium, France, Italy, Spain, Greece and Germany. In Portuguese Island, is where the majority of the learning spaces (four) are located and is also where the learning process starts and finishes. We use a set of figures bellow, to represent and describe the learning spaces and the user behavioral within all the tasks. Due technical conditions, we defined teams with a maximum of 4 students (1 avatar per student), assigning each one with a different color ( 7 colors in the total) to play and achieve the learning tasks - that allow students to know which objects they may interact to identify and execute/solve the learning task/problem.

Firstly, Figure 1 presents the entry point of the serious application, located in the Portuguese Island and called "Terreiro do Paço" (a famous Portuguese square in Lisbon). 


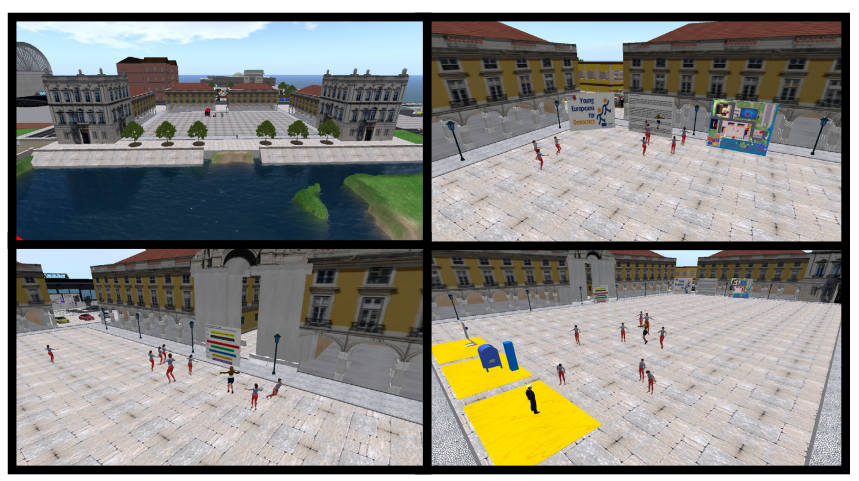

Fig. 1. Terreiro do Paço: The entry point of the serious application, where students know the main goal and rules of the whole game (eg. main narrative, group identification, general scoring and feedback system, objects and interaction ways - accordingly to related affordances and functions that cross-cuts all the learning spaces in the island). Learners are actively engaged in learning some basic controls of the viewer software, useful to interact with objects and characters within the tasks: movement control, camera control, chat, IM, inventory, notecards, touch-based landmarks and teleport, etc. For example, they have to interact with the Map of the Island, mailboxes, teleport buttons (similar to the start buttons of each activity), and with a Portuguese sailor that receives them with a "Welcome aboard" notecard.

Secondly, Figure 2 presents the learning space of the first activity, also located in the Portuguese Island and called "European Union Square".

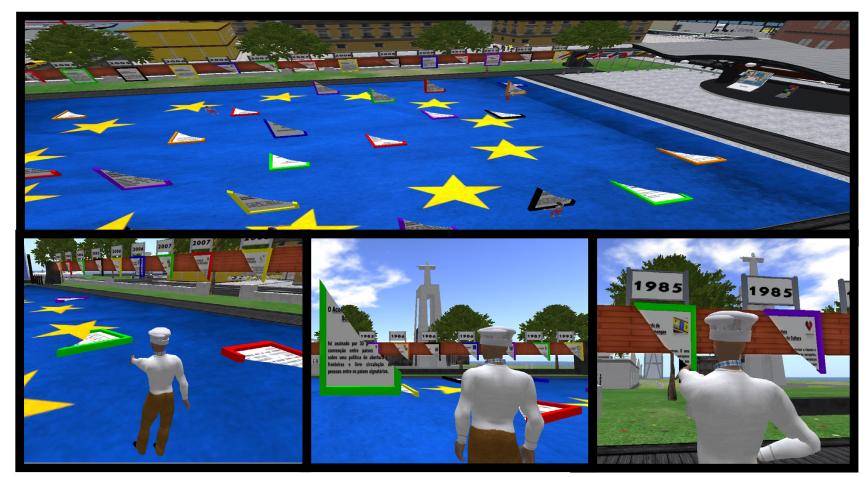

Fig. 2. European Union Square: The learning space of the first activity, where students have to know historically in which facts, symbols, treaties and missions consists the European Union of today, building a 3D collaborative timeline based on a puzzle-solving way. Each team have to touch in a set of 5 pieces of information, scattered around the floor, identified by different colors, and match them with their pairs (placed in the timeline dates). 
Thirdly, Figure 3 presents the learning space of the second activity, also located in the Portuguese Island and called "Citizen Shop" (like Portuguese real-world "Lojas do Cidadão").

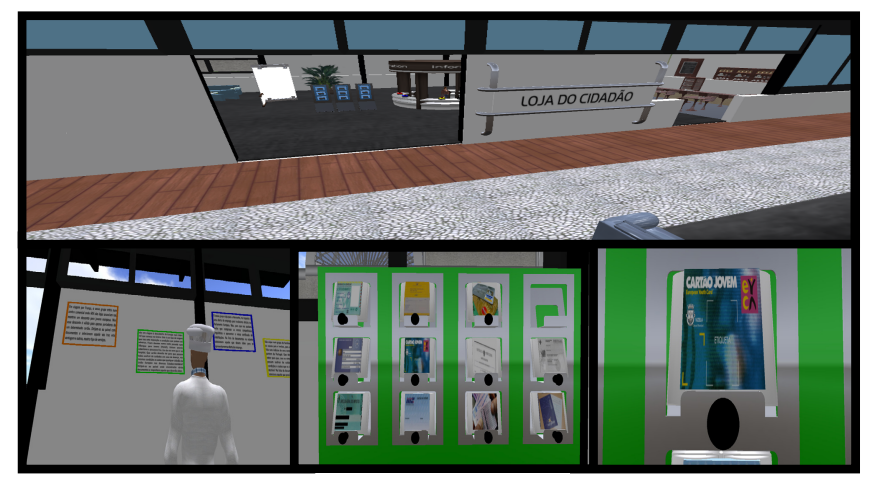

Fig. 3. Citizen Shop: The learning space of the second activity, where students have to find their situation (around its walls) in order to travel to a European Union Member-state (eg. looking for a job due the Portuguese financial crisis; winning a travel package; doing a school exchange; doing an inter-rail, acquire external health care services, etc.). Thereby, they have to check (touching) the necessary documents to travel in a main colored panel (each group have one), accordingly to their different situations.

Fourthly, Figure 4 presents the learning space of the third activity, also located in the Portuguese Island and called "Member-states Park".

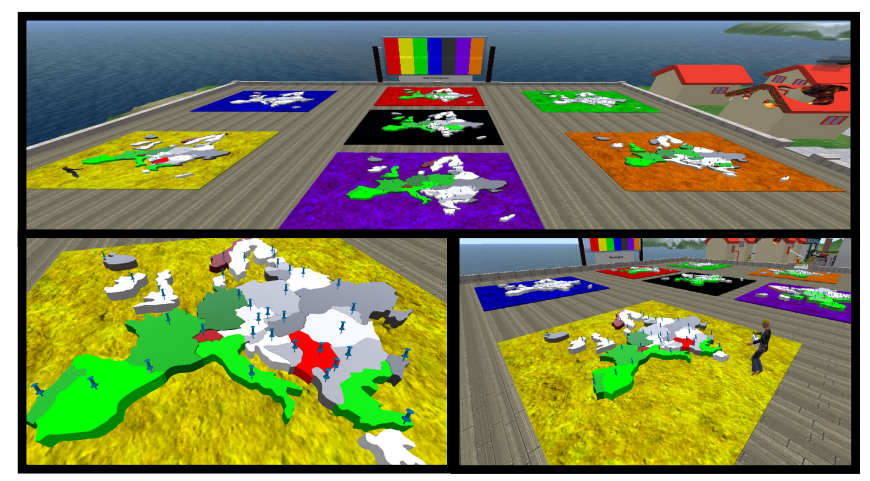

Fig. 4. Member-states Park: The learning space of the third activity, where students have to identify the Member-states and non Member-states of European Union in their team's map. The interaction with the objects is also touch-based, and each object represents an European country.

Fifthly, Figure 5 presents the learning space of the fourth activity, which in turn is located on the different islands of the application (United Kingdom, Belgium, France, Italy, Spain, Greece or Germany). 


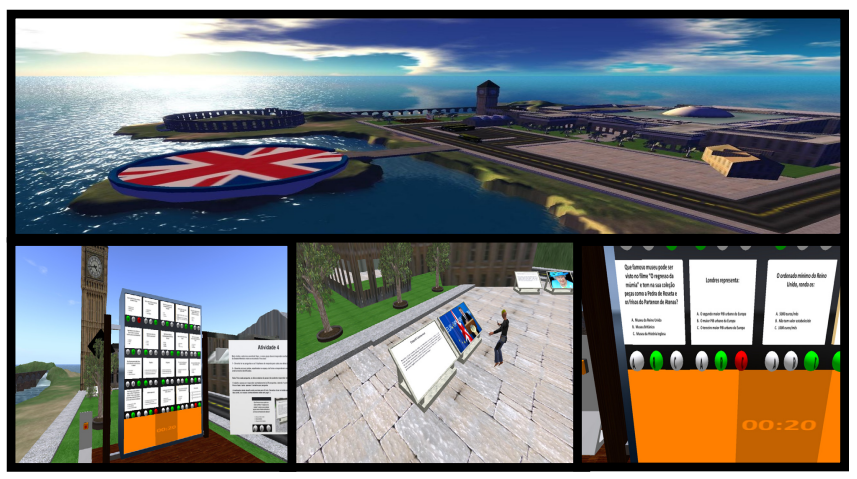

Fig. 5. United Kingdom: One of the different learning spaces of the fourth activity (which changes per group and depends on the situation found in the second activity). The students have to travel to a European Union Member-State, and when arrive there will be a game-clues style based on a multiple-choice question panel to solve. The main goal is to explore the cultural references of each country/space, designed with real-world objects, monuments and symbols (eg. Big Ben, British Museum, Londoner Routemaster bus, etc.), and find useful clues, distributed within the island, in order to select the correct solution/answer of the proposed problems/questions in the panel.

Finally, Figure 6 presents the learning space of the last activity, which is located in the Portuguese Island and called "Police station".

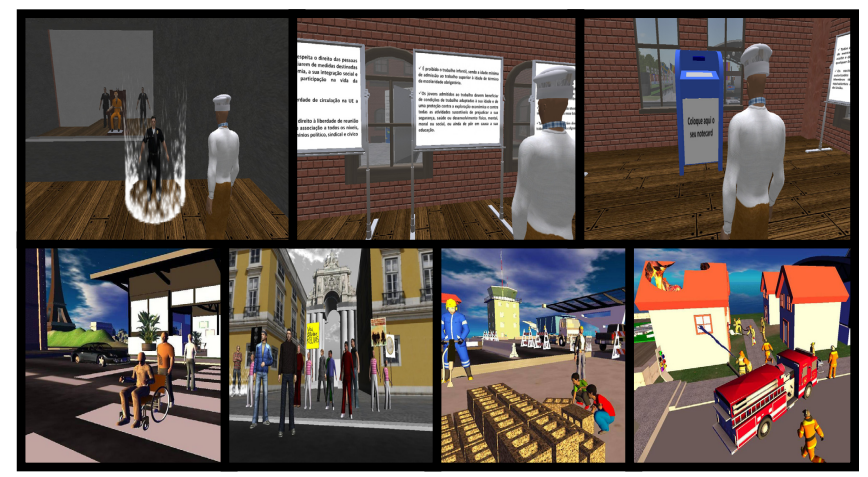

Fig. 6. Police station: The learning space of the fifth and last activity. After the activity 4 , students get back to Portugal and meet a Portuguese police member that needs help, in order to solve different problems related to citizen rights around the island. There are 6 different realworld simulated case-scenarios outside the police station, distributed in the environment, which the teams have to interpret. For this, students have to interact (touch-based) with different characters (clearly identified with a white animated effect), in order to collect notecards with the case-descriptions. Posteriorly, students have to take into account the European Union fundamental rights, identifying the problematic cases (in which the rights are disrespected), and match them with a set of citizen rights, presented with numbers on multiple panels, inside the police station. For that purpose, students should edit each notecard with the matched numbers of the rights. Finally, students have to send all the edited notecards to a blue mailbox. 


\section{$4 \quad$ Preliminary Results and Research Agenda}

We are actually in the fourth main phase of the YED project, delivering workshops with teachers and their classes, where students immerge within their youth citizenship 3D journey. We have followed different session programs, according to the availability of each teacher and class in the project. Some preliminary results are presented here, based on participatory observation within the use of the serious application.

Our finds are in agreement with other two studies [19][20], which suggest that learning was not enhanced and the technology became a distraction. In the majority of the learning spaces, students seems to be less focused on the learning priority content than in the social interaction between other students or secondary content. For instance, when tutors or peers are reading and explaining the instructions for each task, the other students don't stop to chat or editing the avatar appearance. Moreover, in the first activity, we observe that a higher average of students didn't read the information in the pieces as expected, and just simply try to match them without knowing the content.

Another limitation that we found are related to the feedback system. In spite of the students provided with performance feedback information (textual and visual represented) when they interact with the objects in the different tasks, the lack of feedback in beginning and ending of the activities seems to leave some students adrift and confused, with no awareness when the activity started or ended. However, positive aspects has been found. In general, students show high engagement in the use of the 3D Virtual World and a clearly satisfaction related to the different activities, real-world simulated scenarios, and types of user interaction with objects and characters within the spaces. This seems to be related with some of the Minocha \& Reeves design principles [26] that we followed in order to improve the learning experience, such as designing for affordance of the learning spaces, for storytelling, using real world metaphors, consider realism for familiarity and orient the user at the entry point.

Thus, in this first analysis, we noticed the existence of a high level of incidental learning - at least this is some level of engagement that might have some benefits over not engaging at all. However, this surface level of knowledge leads us to think in alternative ways of getting a more in-depth engagement (provided through wellstructured activities with continued feedback over all the steps of each task).

We are collecting data and deepen the analysis on the impact of the project through different instruments and methods. From pre- and post-test, to interviews and questionnaires on the students and teachers expectations, perceptions, and satisfaction regarding the impact of the $3 \mathrm{D}$ serious application in their motivation and engagement for learning and teaching about European Union. Thus, and through the innovative nature of the YED project, we want to measure in-depth, from the user experience point of view, all the potential and limitations of the adopted learning design and user interaction approach. 
Acknowledgments. YED is sponsored by the European Commission's Education \& Culture Directorate-General, under the Lifelong Learning Programme, contract nr. 357639-LLP-2011-PT-AJM-ICS.

\section{References}

1. S.A.R.L., O.: Perceptions of the European Union: A qualitative study of the public's attitudes to and expectations of the European Union in the 15 Member States and in 9 candidate countries. General report, European Commission (2001)

2. Commission, E.: Youth in Europe: a statistical portrait. In: Eurostat Statistic Books. Publications Office of the European Union, Luxemburg (2009)

3. Schuman, R.: The Schuman Declaration. In: Nelson, B., Stubb's, A. (eds.) The European Union: Readings on the Theory and Practice of European Integration, 2nd edn., Macmillan Press Ltd., London (1998)

4. Omale, N., Hung, W., Luetkehans, L., Cooke-Plagwitz, J.: Learning in 3-D multiuser virtual environments: Exploring the use of unique 3-D attributes for online problem-based learning. British Journal of Educational Technology 40(3), 480-495 (2009)

5. de Freitas, S.: Serious virtual worlds: A scoping study. Technical report, Joint Information Systems Commitee. Bristol, UK (2008)

6. Baker, S.C., Wentz, R., Woods, M.: Using virtual worlds in education: Second Life ${ }^{\circledR}$ as an educational tool. Teaching of Psychology 36(1), 59-64 (2009)

7. Lopes, A., Pires, B., Cardoso, M., Santos, A., Peixinho, F., Sequeira, P., Morgado, L.: System for Defining and Reproducing Handball Strategies in Second Life On-Demand for Handball Coaches' Education. In: Proceedings of World Conference on Educational Multimedia, Hypermedia and Telecommunications, ED-MEDIA 2009, vol. 2009, pp. 3954-3961. AACE, Chesapeake (2009)

8. Morgado, L., Varajão, J., Coelho, D., Rodrigues, C., Sancin, C., Castello, V.: The Attributes and Advantages of Virtual Worlds for Real World Training. The Journal of Virtual Worlds and Education 1(1), 2159-9238 (2010)

9. Frias, P., Cruz, R., Fernandes, R.: Second Language Teaching in Virtual Worlds: The Case of European College Students under the ERASMUS Programme. In: Vincenti, G., Braman, J. (eds.) Multi-user Virtual Environments for the Classroom: Practical Approaches to Teaching in Virtual Worlds. IGI Global (2011)

10. Vasileiou, V., Paraskeva, F.: Teaching Role-Playing Instruction in Second Life: An Exploratory Study. Journal of Information Technology and Organizations 5, 25-50 (2010)

11. Vosinakis, S., Koutsabasis, P., Zaharias, P.: An Exploratory Study of Problem-Based Learning in Virtual Worlds. In: 2011 Third International Conference on Games and Virtual Worlds for Serious Applications (VS-GAMES), pp. 112-119. IEEE Computer Society, Washington DC (2011)

12. van der Lan, A.S., Schoutend, P., van den Hooff, B., Feldberg, F.: Modelling the Metaverse: A Theoretical Model of Effective Team Collaboration in 3D Virtual Environments. Journal of Virtual Worlds Research 4(3) (2011)

13. Perez, L.: Challenges and Opportunities in Using MUVEs in K-12 Environments. In: Tettegah, S., Calongne, C. (eds.) Identity, Learning and Support in Virtual Environments, pp. 45-55. Sense Publishers, Rotterdam (2009)

14. Dawley, L.: Social network knowledge construction emerging virtual world pedagogy. On the Horizon 17(2), 109-121 (2009) 
15. Leonard, L.G., Sherblom, J.C., Withers, L.A.: Communication Challenges and Opportunities for Educators Using Second Life. Higher Education in Virtual Worlds Teaching and Learning in Second Life. Emerald Group Publishing Limited (2009)

16. Vilela, A., Cardoso, M., Martins, D., Santos, A., Moreira, L., Paredes, H., Martins, P., Morgado, L.: Privacy challenges and methods for virtual classrooms in Second Life Grid and OpenSimulator. In: 2010 Second International Conference on Games and Virtual Worlds for Serious Applications (VS-GAMES), pp. 167-174. IEEE Computer Society, Washington DC (2010)

17. Dalgarno, B., Lee, M.J.W.: What are the learning affordances of 3-D virtual environments? British Journal of Educational Technology 41(1), 10-32 (2010)

18. Lim, C.P., Nonis, D., Hedberg, J.: Gaming in a 3D multi-user virtual environment (MUVE): Engaging students in Science lessons. British Journal of Educational Technology 37(2), 211-231 (2006)

19. Kanuka, H., Rourke, L., LaFlamme, E.: The influence of instructional methods on the quality of online discussion. British Journal of Educational Technology 38(2), 260-271 (2007)

20. Zaharias, P., Belk, M., Germanakos, P., Samaras, G.: User Experience in Educational Virtual Worlds. In: CHI 2011, ACM 978-1-4503-0268-5/11/05, Vancouver (2011)

21. Hasler, B.S., Buecheler, T., Pfeifer, R.: Collaborative Work in 3D Virtual Environments: A Research Agenda and Operational Framework. In: Ozok, A.A., Zaphiris, P. (eds.) OCSC 2009. LNCS, vol. 5621, pp. 23-32. Springer, Heidelberg (2009)

22. Barab, S.A., Thomas, M., Dodge, T., Carteaux, R., Tuzun, H.: Making learning fun: Quest Atlantis, a game without guns. Educational Technology Research and Development 53(1), 86-108 (2005)

23. Sato, M., Liu, X., Murayama, J., Akahane, K., Isshiki, M.: A Haptic Virtual Environment for Molecular Chemistry Education. In: Pan, Z., Cheok, D.A.D., Müller, W., El Rhalibi, A. (eds.) Transactions on Edutainment I. LNCS, vol. 5080, pp. 28-39. Springer, Heidelberg (2008)

24. Minogue, J., Jones, M.G., Broadwell, B., Oppewall, T.: The impact of haptic augmentation on middle school students' conceptions of the animal cell. Virtual Reality 10(3), 293-305 (2006)

25. Mikropoulos, T.: Presence: a unique characteristic in educational virtual environments. Virtual Reality 10(3), 197-206 (2006)

26. Minocha, S., Reeves, A.J.: Interaction Design and Usability of Learning Spaces in 3D Multi-user Virtual Worlds. Information and Communication Technology, 157-167 (2010)

27. Dominguez, C., Varajão, J., Morgado, L., Oliveira, I., Sousa, F.: SME Managers' Most Important Entrepreneurship and Business Competences. In: Quintela Varajão, J.E., CruzCunha, M.M., Putnik, G.D., Trigo, A. (eds.) CENTERIS 2010. CCIS, vol. 110, pp. 274 282. Springer, Heidelberg (2010) 